\title{
Cerebellar Disorders in Childhood: Cognitive Problems
}

\author{
Maja Steinlin
}

Published online: 5 December 2008

(C) Springer Science + Business Media, LLC 2008

\begin{abstract}
Over the last decade, increasing evidence of cognitive functions of the cerebellum during development and learning processes could be ascertained. Posterior fossa malformations such as cerebellar hypoplasia or Joubert syndrome are known to be related to developmental problems in a marked to moderate extent. More detailed analyses reveal special deficits in attention, processing speed, visuospatial functions, and language. A study about Dandy Walker syndrome states a relationship of abnormalities in vermis lobulation with developmental problems. Further lobulation or volume abnormalities of the cerebellum and/or vermis can be detected in disorders as fragile $\mathrm{X}$ syndrome, Downs's syndrome, William's syndrome, and autism. Neuropsychological studies reveal a relation of dyslexia and attention deficit disorder with cerebellar functions. These functional studies are supported by structural abnormalities in neuroimaging in these disorders. Acquired cerebellar or vermis atrophy was found in groups of children with developmental problems such as prenatal alcohol exposure or extreme prematurity. Also, focal lesions during childhood or adolescence such as cerebellar tumor or stroke are related with neuropsychological abnormalities, which are most pronounced in visuospatial, language, and memory functions. In addition, cerebellar atrophy was shown to be a bad prognostic factor considering cognitive outcome in children after brain trauma and leukemia. In ataxia teleangiectasia, a neurodegenerative disorder affecting primarily the cerebellar cortex, a reduced verbal intelligence quotient and problems of judgment of
\end{abstract}

\section{Steinlin $(\varangle)$}

Neuropaediatrics, University Children’s Hospital, Inselspital,

3010 Bern, Switzerland

e-mail: maja.steinlin@insel.ch duration are a hint of the importance of the cerebellum in cognition. In conclusion, the cerebellum seems to play an important role in many higher cognitive functions, especially in learning. There is a suggestion that the earlier the incorrect influence, the more pronounced the problems.

Keywords Cerebellum · Cognition · Neuropsychology · Development. Children

For a long time, the cerebellum has been known for its importance in motor learning and coordination. Over the last decades, it became more and more evident that a correct interplay between cerebellum and cerebrum is also necessary for cognitive functions [1, 2]. Part of the cerebellar functions are within the area of learning or habituation. As any child during development has a high need to achieve and improve new functions, it is not surprising that early-onset cerebellar dysfunction leads to pronounced cognitive developmental problems.

\section{Posterior Fossa Malformations}

Congenital malformations of the cerebellum are known to be associated with developmental problems. Children with cerebellar hypoplasia present not only with congenital ataxia but also with mild to moderate speech and cognitive developmental problems [3, 4]. In our group of patients, more detailed neuropsychological examinations revealed intelligence quotient (IQ) values ranging from 30 to low normal values; most affected areas were attention, processing speed, and visuospatial functions. The neuropsychological profile (asymmetric, with verbal functions being superior to nonverbal functions) suggests that possible longstanding deficits in visuospatial input during learning 
and the influence of impaired procedural learning might be important.

Children within the group of syndromes with the molar tooth sign usually have significant developmental problems. In a group of children with Joubert syndrome (vermis aplasia) we were able to show that at long-term follow-up these children had IQs ranging from $<30$ to 85 [5], results which have since been confirmed in other groups of Joubert patients $[6,7,8]$.

In general, syndromes with cerebellar abnormalities are related with developmental problems. But there seems to be one exception: approximatively $50 \%$ of children with Dandy Walker malformations are reported to have a normal cognitive development [9, 10]. Boddaert et al. [9] revealed that normal cognitive development in children with Dandy Walker malformations was related to normal vermian lobulation. These data point to the great importance of the vermis for the early development of cognitive functions.

All the above malformation syndromes have their major abnormality in the cerebellum. However, accompanying abnormalities of brainstem (as known in Joubert syndrome) and/or cerebrum might also have an influence on cognitive functions. Thus, the cerebellar role for the cognitive problems in these children seems to be important, but additional cerebral dysfunction cannot be ruled out.

\section{Abnormalities of Cerebellar Volumes and Structures}

Structural imaging studies and especially volumetric studies in several disorders, such as fragile $\mathrm{X}$ syndrome, dyslexia, and attention-deficit/hyperactivity disorder (ADHD), further support the assumption of cerebellar cognitive functions. In fragile $X$ syndrome, there is a decrease of size in the posterior vermis. In female and male premutation carriers, these vermal abnormalities are related to their cognitive problems [11, 12]. In Williams's syndrome, an enlarged cerebellum with abnormalities in phosphor and proton magnetic resonance (MR) spectroscopy could be found $[13,14]$. There was a significant correlation between cerebellar ratios Cho/NA and Cre/NA and the ability of the subjects in various neuropsychological tests.

Interestingly, recent studies discuss the hypothesis of "cerebellar dyslexia of Nicolson" suggesting that cerebellar deficits at birth lead to phonological, processing speed, and literacy problems by problems of articulation and working memory [15]. This hypothesis is supported by recent findings of Stoodley [16] which show dyslexic adults to have an implicit learning problem, a primarily cerebellar function. In addition, the cerebellum is one of the most consistent locations for structural differences between dyslexic and control participants in imaging studies [17]. Moreover, Moretti et al. [18] published results of ten patients with acquired vermian or paravermian lesions, all of which showed an increased number of reading mistakes. In addition to cerebellar dysfunction, oculomotor abnormalities or disturbed cerebellar encephalic projections must also be considered to be related to these findings.

Attention deficit disorder (ADD) is another behavioral developmental problem which might have a relation to the cerebellum. Vermal volume was found to be smaller and with abnormalities in the posterior lobe VI-VIII in boys with ADHD compared to healthy controls [19]. Berquin suggests that a cerebellar-thalamo-prefrontal circuit dysfunction may subserve the deficits encountered in ADD. Functional MR studies give evidence that ADD is a problem related to the frontal lobe; however cerebellar-frontal connections are prominent, and thus, accompanying cerebellar problems cannot be ruled out. A functional MR study looking at baseline activity showed bilateral cerebellar and vermis alteration in addition to frontal and parietal changes [20].

Many studies discuss the role of the cerebellum in autism. Different aspects of changes in volume and size of the cerebellum compared to cerebral lobes are discussed $[21,22]$. Recent studies suggest an immunological influence on pathophysiology of autism by detecting autoantibodies against cerebellar neural cells [23]. Rout and Dhossche suggest a hypothetic model, where anti-glutamate acid decarboxylase (GAD) antibodies against Purkinje cells might be an important trigger factor in the origin of autism. [24].

Although cerebellar contribution to cognitive problems is highly suggestive by these volumetric and structural abnormalities, a secondary transsynaptic effect on the cerebellum by abnormalities/dysfunction of other cerebral regions have to be considered. However, transsynaptic effect cannot explain all findings; a model with a disturbed interplay between cerebellum and cerebrum might explain the cognitive dysfunction observed in these children.

\section{Pre- and Perinatally Acquired Cerebellar Abnormalities}

Prenatal alcohol exposure leads to a decrease of anterior vermis volume [25, 26, 27, 28]. Anterior vermal dysmorphology was negatively correlated with verbal learning and memory performance within the alcohol-exposed group [30].

Cerebellar lesions and atrophy are also important in preterm children; marked cerebellar atrophy is related to severe developmental problems [29]. Extremely premature children are prone to have injuries to the inferior cerebellar hemispheres and/or vermis [30, 31]. Accompanying cerebral lesions mostly are of less severe nature. Beside motor impairment, the clinical features of these preterms included significant developmental problems in cognitive functions and language. Limperopoulos et al. [32] suggest that reduction of cerebellar volume and cerebral lesions are 
related to trophic transsynaptic effects. However, not only cerebellar atrophy is a signpost for possible cognitive problems in preterm children but also cerebellar hemorrhage seems to have a similar effect in this group [33], thus suggesting at least some primary effect by the cerebellar lesion.

\section{Acquired Cerebellar Lesions During Childhood}

In view of the uncertainties in the cerebellar role for cognitive problems in these many syndromes, acquired focal cerebellar lesions are more adequate models for the analyses of cognitive functions of the cerebellum. Levisohn [34] studied a group of 19 children with infratentorial tumors. These children showed a specific pattern of neuropsychological problems with visuospatial, language sequencing and memory problems. These results could in large be confirmed by a study of Riva et al. [35], our own study [36], and several other reports since. The largest series of 103 children after tumor resection alone was reported by Beebe et al. [37]. They detected no specific profile and no localization-related deficit. However, as a group, these children showed widespread effects, most pronounced on performance IQ, spelling, adaptive behavior, and full-scale IQ. Coexisting motor problems could not explain fully all these abnormalities. Hints for localizationrelated problems were given by Scott et al. [38]: In a small group of seven children, greater damage to the right hemisphere led to a plateau in verbal and/or literacy skills, and greater involvement of the left hemisphere led to impaired nonverbal/visuospatial skills.

An important observation is also the appearance of cerebellar mutism after infratentorial surgery [39], followed by dysarthria on long term. Paquier et al. [39] suggest that the underlying pathophysiology for mutism is a disturbed mental initiation which precedes the programming of any intentional bucco-phonatory movements. In a case study of Kusano et al. [40], bilateral but not unilateral destruction of the dentate nuclei was followed by mutism. Papavasilou et al. [41] report on a case of mutism following diffuse cerebellitis.

Focal lesions like stroke in the cerebellum are even better suited for characterizing specific cerebellar functions and dysfunctions, respectively. There is one report of a group of young adults with pure cerebellar infarcts also revealing impairment in central aspects of attention and visuospatial skills [42]. Due to their cognitive problems, two thirds of these patients could not return to work 12 months after the acute event. In our own study of children after arterial ischemic stroke, we follow so far one previously completely healthy child who suffered a pure cerebellar childhood infarction (superior cerebellar artery left-sided). At follow-up 2 years later, she had a general IQ of 88 with marked problems in short-term memory. This supports not only the influence of the cerebellum in cognitive functions but also its role in attention.

Another model of cerebellar-acquired lesion is ataxia teleangiectasia (AT), which is known to affect primarily the cerebellar cortex. In 17 patients with AT, Mostofsky et al. [43] observed a significantly lower verbal IQ and a significant problem with judgment of duration after correcting for their lower verbal IQ. These findings support the important role of the cerebellum in timing.

In addition, there are several reports which show that neurocognitive problems after generalized brain events are related to cerebellar or vermis atrophy, as can be observed in children after head trauma [44] or in survivors of leukemia [45].

In conclusion, the cerebellum seems to play an important role in many higher cognitive functions. Motor and oculomotor problems alone cannot explain all these findings. However, many of the above-summarized problems are also related with cerebral structural or functional abnormalities or microstructural abnormalities of connections from cerebellum to pons or cerebrum. Thus, a model with an incorrect interplay between cerebellum and cerebrum might explain best the wide variety of neuropsychological, speech, and learning problems seen in children with cerebellar disorders. The earlier the incorrect influence occurs, the more pronounced the problems will be, explaining the considerably more expressed developmental problems in children with primary cerebellar disorders compared to later acquired lesions. One might hypothesize that the most important or primary function of the cerebellum is learning, either during development or later during rehabilitation processes. Once the function is well mastered by the cerebrum, the importance of the cerebellum might decline.

\section{References}

1. Schmahmann JD, Sherman JC (1998) The cerebellar cognitive affective syndrome. Brain 121:561-567

2. Rapoport M, van Reekum R, Mayberg H (2000) The role of the cerebellum in cognition and behaviour: a selective review. J Neuropsychiatry Clin Neurosci 12:193-198

3. Shevell MI, Majnemer A (1996) Clinical features of developmental disability associated with cerebellar hypoplasia. Pediatr Neurol 15:224-229

4. Steinlin M, Styger M, Boltshauer E (1999) Cognitive impairments in patients with congenital nonprogressive cerebellar ataxia. Neurology 53:966-973

5. Steinlin M, Schmid M, Landau K, Boltshauser E (1997) Follow-up in children with Joubert syndrome. Neuropediatrics 28:204-211

6. Fenell EB, Gitten JC, Dede DE, Maria BL (1999) Cognition, behavior, and development in Joubert syndrome. J Child Neurol 14:592-596 
7. Barreirinho MS, Teixeira J, Moreira NG, Bastos S, Goncalvez S, Barbot MC (2001) Joubert's syndrome: report of 12 cases. Rev Neurol 32:812-817

8. Hodgkins PR, Harris CM, Shawkat FS, Thompson DA, Chong K, Timms C et al (2004) Joubert Syndrome: long term follow-up. Dev Med Child Neurol 46:694-699

9. Boddaert N, Klein O, Ferguson N, Sonigo P, Parisot D, HertzPannier L et al (2003) Intellectual prognosis of the Dandy-Walker malformation in children: the importance of vermian lobulation. Neuroradiology 45:320-324

10. Gerszten PC, Albright AL (1995) Relationship between cerebellar appearance and function in children with Dandy-Walker syndrome. Paediatr Neurosrurg 23:86-92

11. Mostofksy SH, Mazzocco MM, Aakalu G, Warsofsky IS, Denckla MG, Reiss AL (1998) Decreased cerebellar posterior vermis size in fragile $\mathrm{X}$ syndrome: correlation with neurocognitive performance. Neurology 50:121-130

12. Cornish K, Kogan C, Turk J, Manly T, James N, Mills A et al (2005) The emerging fragile X premutation phenotype: evidence from the domain of social cognition. Brain Cogn 57:53-60

13. Jones W, Hesselink J, Courchesne E, Duncan T, Matsuda K, Bellugi U (2002) Cerebellar abnormalities in infants and toddlers with Williams syndrome. Dev Med Child Neurol 44:688-694

14. Rae C, Karmiloff-Smith A, Less MA, Dixon RM, Grant J, Blamire AM et al (1998) Brain biochemistry in Williams syndrome: evidence for a role of the cerebellum in cognition. Neurology 51:33-40

15. Nicolson R, Fawcett AJ, Dean P (2001) Dyslexia, development and the cerebellum. Trends Neurosci 24:515-516

16. Stoodley CJ, Harrison EP, Stein JF (2006) Implicit motor learning deficits in dyslexic adults. Neuropsychologia 44:795-798

17. Eckert MA, Leonard CM, Richards RL, Aylward EH, Thomson J, Berninger VW (2003) Anatomical correlates of dyslexia: frontal and cerebellar findings. Brain 126:482-494

18. Moretti R, Bava A, Torre P, Antonello RM, Cazzato G (2002) Reading errors in patients with cerebellar vermis lesions. J Neurol 249:461-468

19. Berquin PC, Gliedd JN, Jacobsen LK, Hamburger SD, Krain AL, Rapoport JL et al (1998) Cerebellum in attention-deficit hyperactivity disorder: a morphometric MRI study. Neurology 50:10871093

20. Zang YF, Yong H, Chao-Zhe Z, Qing-Jiu C, Man-Qiu S, Meng L et al (2007) Altered baseline brain activity in children with ADHD revealed by resting-state functional MRI. Brain Dev 29:83-91

21. Hallahan B, Daly EM, McAlonan G, Loth E, Toal F, O'Brien F et al (2008) Brain morphometry volume in autistic spectrum disorder: a magnetic resonance imaging study of adults. Psychol Med 8:1-10

22. Amaral DG, Schumann CM, Nordahl CW (2008) Neuroanatomy of autism. Trends Neurosci 31:137-145

23. Wills S, Cabanlit M, Bennett J, Asthwood P, Amaral DG, Van de4 Water J (2008)_Detection of autoantibodies to neural cells of the cerebellum in the plasma of subjects with autism spectrum disorders. Brain Behav Immun (in press). doi:10.1016/j.bbi.2008.07.007

24. Rout UK, Dhossche DM (2008) A pathogenetic model of autism involving Purkinje cell loss through anti-GAD antibodies. Med Hypotheses 71:218-221

25. Sowell ER, Jernigan TL, Mattson SN, Riley EP, Sobel DF, Jones KL (1996) Abnormal development of the cerebellar vermis in children prenatally exposed to alcohol: size reduction in lobules IV. Alcohol Clin Exp Res 20:31-34

26. Autti-Ramo I, Autti T, Korkman M, Kettunen S, Salonen O, Valanne L (2002) MRI findings in children with school problems who had been exposed prenatally to alcohol. Dev Med Child Neurol 44:98-106
27. Roebuck TM, Mattson SN, Riley EP (1998) A review of the neuroanatomical findings in children with fetal alcohol syndrome or prenatal exposure to alcohol. Alcohol Clin Exp Res 22:339-344

28. O'Hare ED, Kan E, Yoshii J, Mattson SN, Riley EP, Thompson PM et al (2005) Mapping cerebellar vermal morphology and cognitive correlates in prenatal alcohol exposure. Neuroreport 16:1285-1290

29. Krägeloh-Mann I, Toft P, Lunding J, Andresen J, Pryds O, Lou HC (1999) Brain lesions in preterms: origin, consequences and compensation. Acta Paediatr 88:897-908

30. Johnsen SD, Tarby TJ, Lewis KS, Bird R, Prenger E (2002) Cerebellar infarction: an unrecognized complication of very low birthweight. J Child Neurol 17:320-324

31. Johnsen SD, Bodensteiner JB, Lotze TE (2005) Frequency and nature of cerebellar injury in the extremely premature survivor with cerebral palsy. J Child Neurol 20:60-64

32. Limperopoulos C, Soul JS, Haidar H, Huppi PS, Bassan H, Warfield SK et al (2005) Impaired trophic interactions between the cerebellum and the cerebrum among preterm infants. Pediatrics 116:844-850

33. Limperopoulos C, Benson CB, Bassan H, Disalvo DN, Kinnamon $\mathrm{DD}$, Moore $\mathrm{M}$ et al (2005) Cerebellar hemorrhage in the preterm infant: ultrasonographic findings and risk factors. Pediatrics $M$ 116:717-724

34. Levisohn L, Cronin-Golomb A, Schmahmann JD (2000) Neuropsychological consequences of cerebellar tumour resection in children: cerebellar cognitive affective syndrome in a paediatric population. Brain 123:1041-1050

35. Riva D, Giorgi C (2000) The cerebellum contributes to higher functions during development: evidence from a series of children surgically treated for posterior fossa tumours. Brain 123:1051-1061

36. Steinlin M, Imfeld S, Zulauf $P$, Boltshauser E, Ridolfi-Lüthi A, Lövblad KO, Perrig W, Kaufmann F (2003) Neuropsychological long term sequelae after posterior fossa tumor resection during childhood. Brain 126:1998-2008

37. Beebe DW, Ris MD, Armstrong FD, Fontanesi J, Mulhern R, Holmes E (2005) Cognitive and adaptive outcome in low-grade paediatric cerebellar astrocytomas: evidence of diminished cognitive and adaptive functioning in National Collaborative Research Studies [CCG 9891/POG 9130]. J Clin Oncol 23(22):5198-5204

38. Scott RB, Stoodley CJ, Anslow P, Paul C, Stein JF, Sugden EM et al (2001) Lateralized cognitive deficits in children following cerebellar lesions. Dev Med Child Neurol 43:685-691

39. Paquier P, van Mourik M, van Dongen $H$, Catsman-Berrevoets $C$, Brison A (2003) Cerebellar mutism syndromes with subsequent dysarthria: a study of three children and a review of the literature. Rev Neurol 159:1017-1027

40. Kursano Y, Tanaka Y, Takasanua H, Wada N, Tada T, Kakizawa Y, Hongo K (2006) Transient cerebellar mutism caused by bilateral damage to the dentate nuclei after the second posterior fossa surgery. J Neurosurg 104:329-331

41. Papavasilou AS, Kotsalis C, Trakadas S (2004) Transient cerebellar mutism in the course of acute cerebellitis. Pediatr neruol 30:71-74

42. Malm J, Kristensen B, Karlsson T, Carlberg B, Fagerlund M, Olsson T (1998) Cognitive impairment in young adults with infratentorial infarcts. Neurology 51:433-440

43. Mostofsky SH, Kunze JC, Cutting LE, Lederman HM, Denckla MB (2000) Judgment of duration in individuals with ataxiatelangiectasia. Dev Neuropsychol 17:63-74

44. Soto Ares G, Vinchon M, Delmaire C, Abecidan E, Dheliemes P, Pruvo JP (2001) Cerebellar atrophy after severe traumatic head injury in children. Childs Nerv Syst 17:263-269

45. Ciesielski KT, Yanofsky R, Ludwig RN, Hill DE, Hart BL, Astur RS et al (1994) Hypoplasia of the cerebellar vermis and cognitive deficits in survivors of childhood leukemia. Arch Neurol 51:985-993 